Scientific Visualization, 2020, volume 12, number 5, pages 37 - 45, DOI: 10.26583/sv.12.5.04

\title{
Visualization of coolant flow in the model of a nuclear reactor pressure vessel
}

\author{
A.A. Dobrov ${ }^{1}$, D.V. Doronkov², A.V. Ryazanov3, A.E. Khrobostov ${ }^{4}$ \\ Nizhny Novgorod State Technical University n.a. R.E. Alekseev \\ ${ }^{1}$ ORCID: 0ooo-0001-7363-8791, dobrov@nntu.ru \\ 2 ORCID: 0000-0003-0668-4215, nevidooo@mail.ru \\ 3 ORCID: 0000-0002-4951-8930, a v ryazanov@rambler.ru \\ 4 ORCID: 0000-0002-6349-2861, khrobostov@nntu.ru
}

\begin{abstract}
The article is devoted to visualization of the results of experimental work aimed at studying the turbulent flow of the coolant in the model of the lower chamber of a nuclear reactor. Using the method of tracer injection into one of the four loops of coolant circulation, we studied the mixing process of coolant flow in the lower chamber of the reactor. Based on the experiment, the values of the tracer volume fraction at individual points of the model are obtained. To visualize the results, the Matlab software package was used. Obtained during the processing of the experimental data, the tracer volume fraction fields in the characteristic areas of the lower chamber model made it possible to analyze the features of the motion and mixing of the loop coolant flows. The effect of swirling the coolant flow in the lower channel and in the lower pressure chamber of the model was experimentally obtained and visualized.
\end{abstract}

Keywords: mixing, tracer method, nuclear reactor.

\section{Introduction}

The creation of new pressurized water reactors requires a complex of research works to justify the safety of both new design solutions and reactor's operation modes. Justification of thermal reliability is largely based on thermal-hydraulic calculation, which requires informative and reliable parameters of the coolant, taking into account their local distribution inside the reactor.

One of the issues of determining the thermal-hydraulic efficiency of the nuclear reactor is the study of the mixing processes of coolant flows entering the reactor's lower chamber through several circulation loops. Such studies allow us to clarify the temperature distribution at the core inlet and in the coolant circulation loops, which is especially important in the operation modes of a reactor with an asymmetric load [1-4]. The results of such studies are also necessary for calculating the distribution of boric acid concentration in the core when it is injected into the coolant [5-8].

\section{Experimental facility}

Experimental facility FT-50 of Nizhny Novgorod State Technical University n.a. R.E. Alekseev (Fig. 1) is an aerodynamic open loop. It was designed for research of local values of flow velocity and pressure, as well as mixing of coolant in models of main equipment of nuclear reactors [10-13]. The stand includes: high-pressure fan, receiver tank, pipeline system, experimental model, measuring devices. 


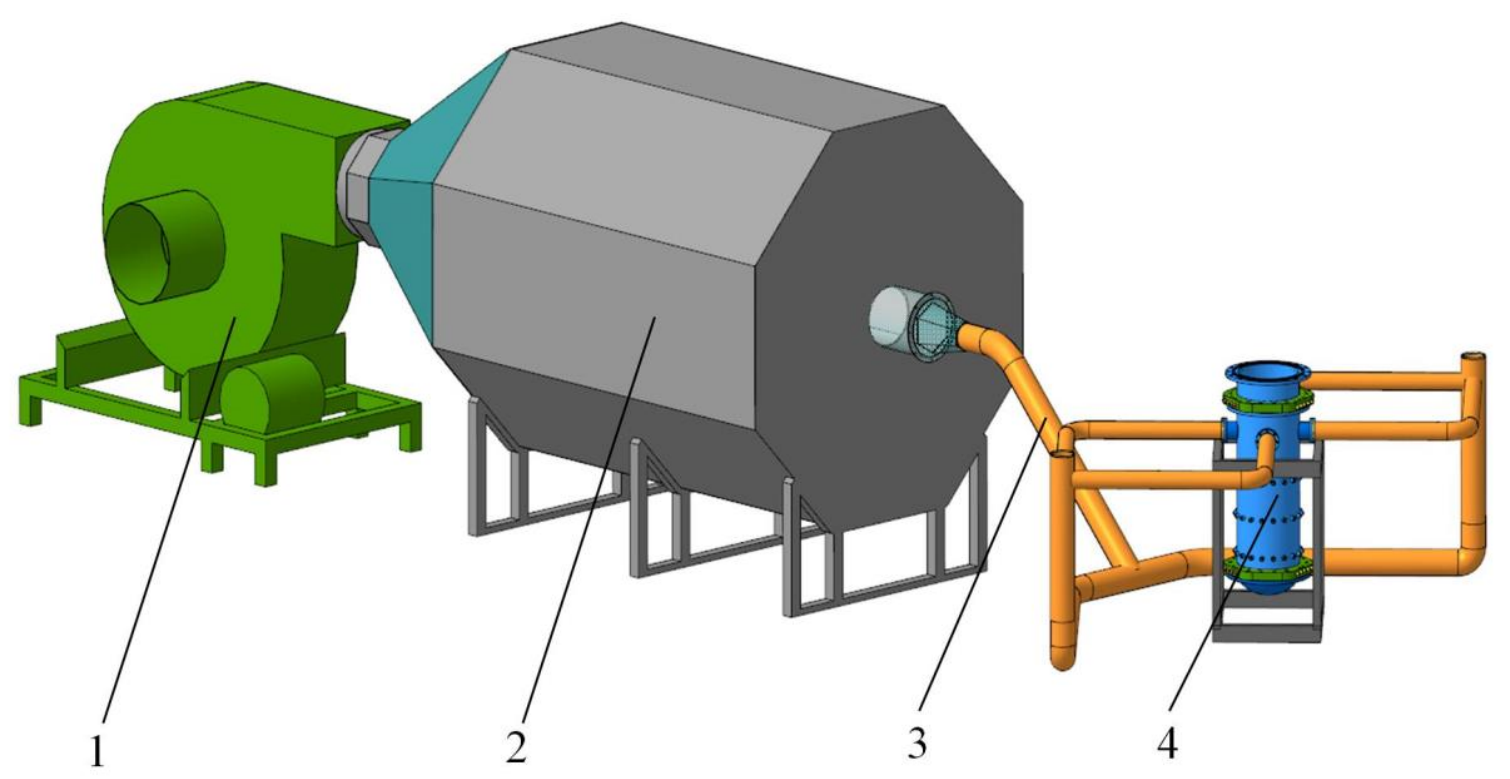

Fig. 1. General view of the experimental stand FT-50: 1 - high-pressure fan; 2 - receiver tank; 3 - pipeline system; 4 - experimental model of reactor pressure vessel.

\section{Experimental model}

The experimental model (Fig. 2) is a simplified scaled model of the pressure vessel of a nuclear reactor with four coolant circulation loops [14].
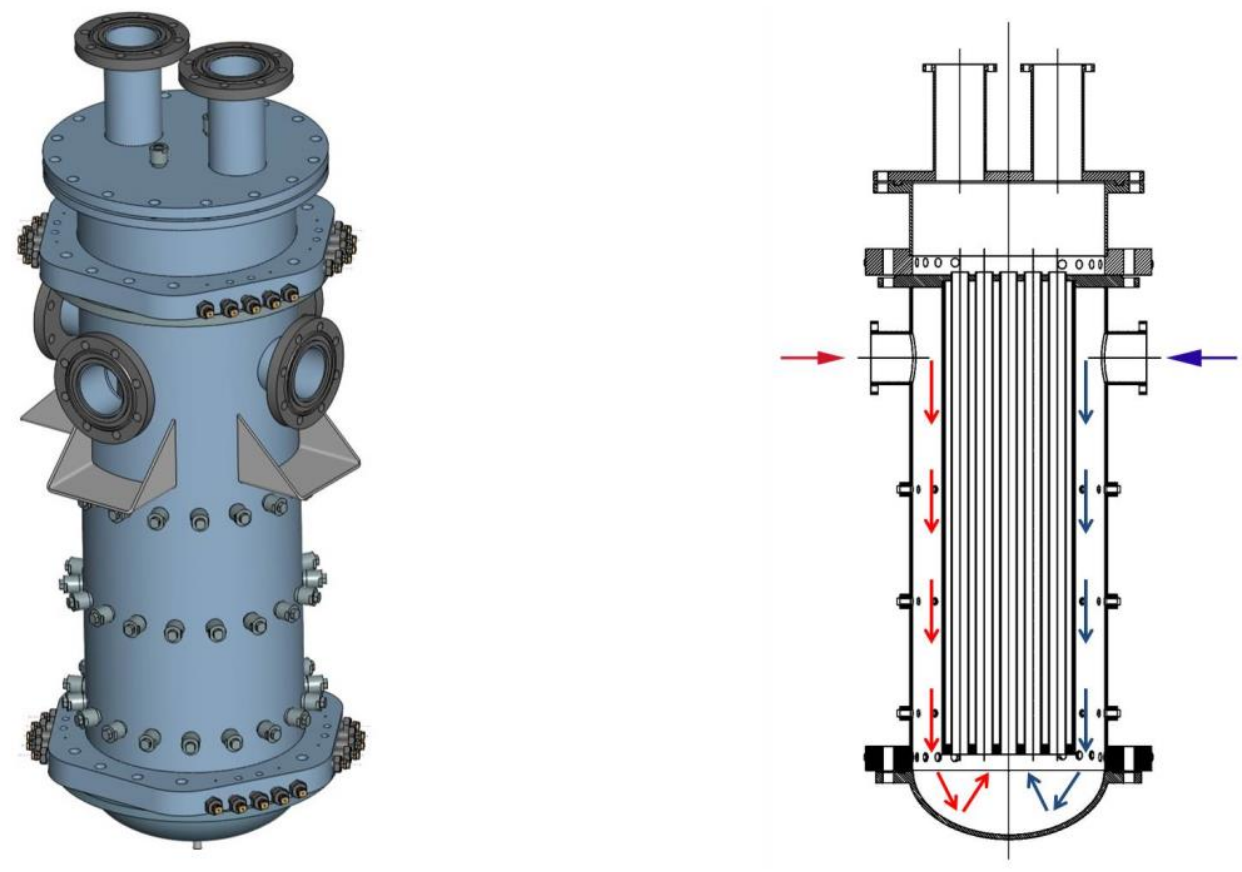

Fig. 2. Experimental model of reactor pressure vessel.

The movement of the coolant is as follows: the coolant flows into the model through four radial pipes, then descends in an annular channel to the lower pressure chamber. From there it is distributed across the channels that simulate the reactor core. The pipes are located at an angle of 90 degrees to each other. The core simulator is a set of nineteen throttled vertical channels that simulate pressure drop in the core. 


\section{Experimental research methodology}

Air was pumped into all four pipes of the model in the experiment. For three of the pipes, the air pumped in was clean, and for the fourth one, the air contained a gaseous admixture. This "asymmetric" mode is schematically shown in Fig 3.

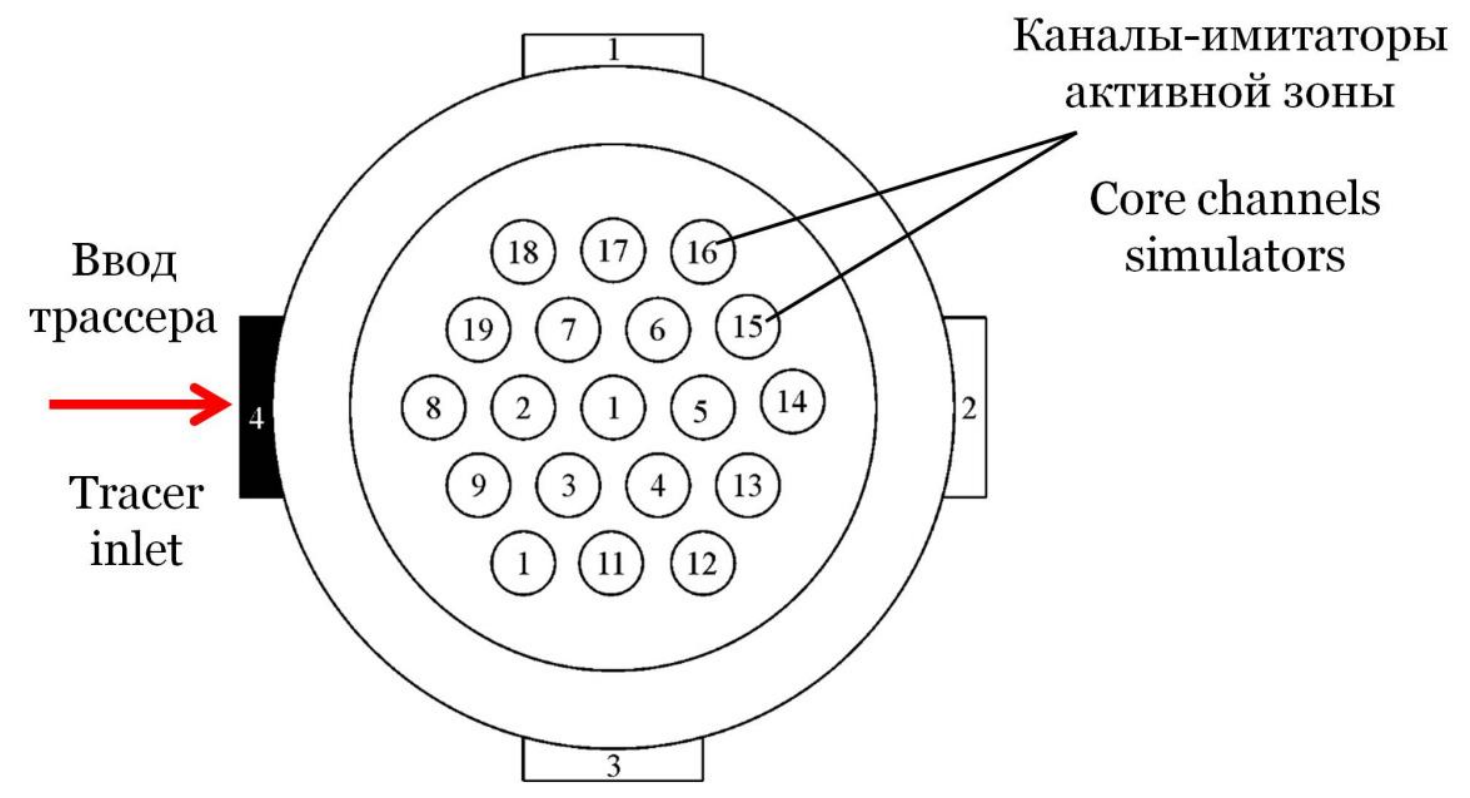

Fig. 3. "Asymmetric" mode organized in the experiment (top view of the model).

The air flow rates in each loop were set and maintained the same. This paper presents results for one of the experimental modes, which corresponds to the value of the Reynolds number $R e=20000$. The Reynolds number was determined by the cross section of the descending annular channel of the model. The series of experiments at the NNSTU test facilities include variation of the Reynolds number by changing individual parameters contained in it: flow velocity and kinematic viscosity (using different fluids - air and water and its heating), in the range $R e=10000 \div 50000$.

The study of the features of the coolant flow inside the reactor model was carried out using the tracer method (contrastive passive admixture), for which propane was chosen. The presence of this gas in small quantities in the air under convective high-turbulent flow does not affect the flow.

Injection of propane to the experimental aerodynamic model allows us to visually study the characteristics of the coolant in the process of inter loop mixing [15-17]. The volume concentration of propane in the air stream did not exceed 1200 ppm (tracer injection pipe), which is significantly less than the concentration of explosive mixture formation (at least $17000 \mathrm{ppm})$. But such values can be measured with satisfactory accuracy $( \pm 15 \mathrm{ppm})$ using a gas analyzer, the principle of which is based on measuring the amount of absorption of infrared radiation in a measuring cell through which the measured gas-air mixture is pumped.

To study the mixing process of loop coolant flows in the model of a nuclear reactor, two areas of the model were selected as characteristic areas: annular channel and pressure chamber (Fig. 4). 
Области изучения процессов:

1 - опускной кольцевой канал;

2 - нижняя напорная камера

Areas of the model selected for research:

1 - annular channel;

2 - pressure chamber

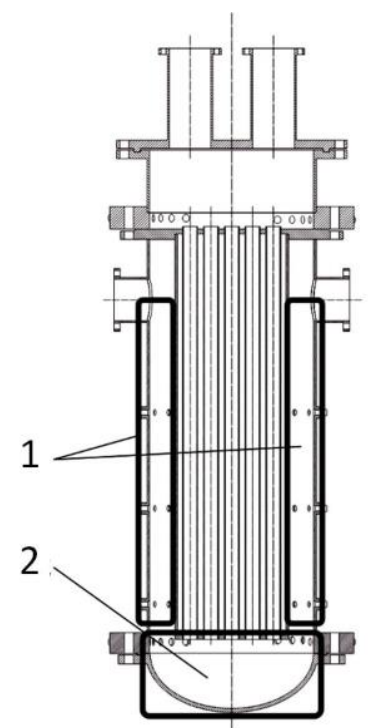

Fig. 4. Areas of the model selected for research

The gas concentration in the annular channel was measured using a L-shaped tube $\varnothing_{4 \times 0.5}$ $\mathrm{mm}$, introduced into the model through fittings located on the model body at three height levels (height step $220 \mathrm{~mm}$ ). At each level along the perimeter, measurements were carried out at 20 points separated by 20 degrees from each other. The L-shaped probe was positioned on the average diameter of the annular channel.

The gas concentration in the pressure chamber was measured using direct probes from $\varnothing_{4} \times 0.5 \mathrm{~mm}$ tubes installed at the entrances to the channels simulating the reactor core.

\section{Visualization of the coolant flow in the annular chan- nel of the reactor model}

The results were processed in the Matlab software package, which has an extensive library of mathematical and graphical data processing functions, and also allows creating user scripts and compiling applications for Windows based on them.

This visualization of the tracer distribution in the annular channel consisted of the following: graphical construction of a cylindrical surface with dimensions corresponding to the model geometry; interpolation of numerical values of the tracer concentration measured at individual points on this surface; drawing as a $3 \mathrm{D}$ contour plot.

This procedure can be implemented in the Matlab program as follows:

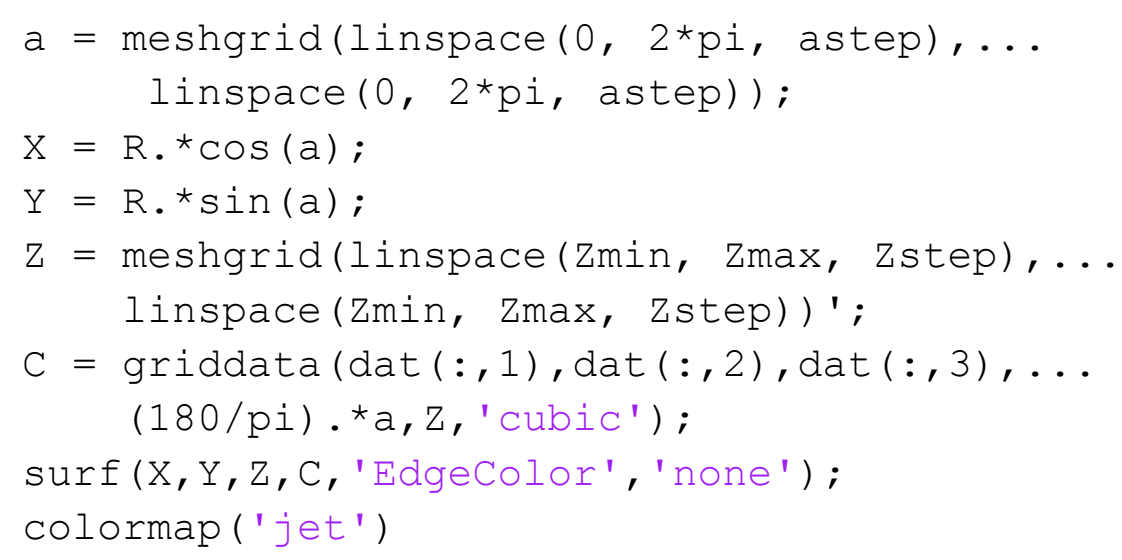

a - the variable with the coordinates of mesh nodes along the angular coordinate;

astep - step of arrangement of grid nodes by angular coordinate;

$X, Y, \quad Z$ - coordinates of grid nodes in the Cartesian system; 
$R$ - radius of the cylindrical surface;

Zmin, Zmax, Zstep - minimum and maximum values of the $Z$ coordinate and the height step of the grid;

$\mathrm{C}$ - interpolated field of the tracer concentration;

dat - a matrix containing experimental data $\left(1^{\text {st }}\right.$ column - angular coordinates of measurement points, $2^{\text {nd }}$ column - coordinates of points in height, $3^{\text {rd }}$ column - measured values of tracer concentration).

The result of this procedure is shown in Fig. 5 .

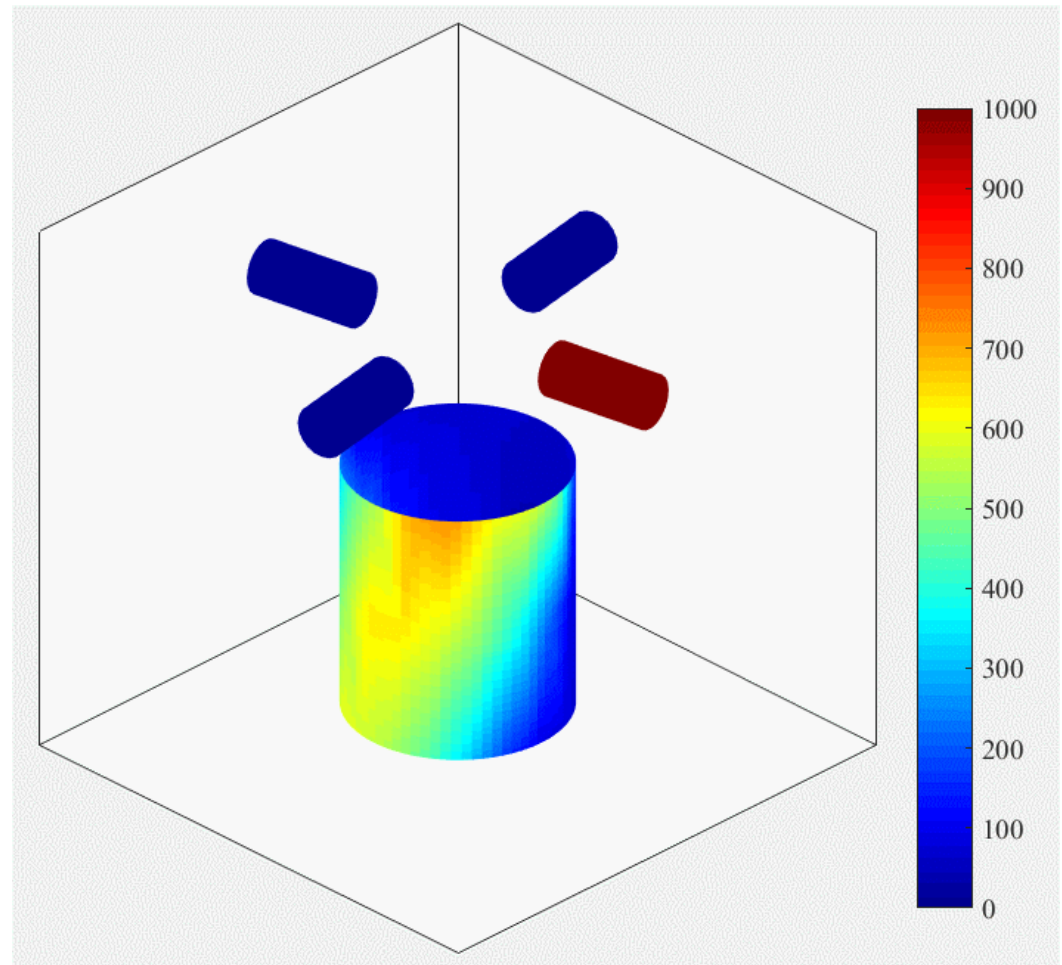

Fig. 5. Visualization of the experimental tracer distribution in the model's annular channel

( $R e=20000$; color-over by volume concentration values in $\mathrm{ppm}$ ).

From Fig. 5, it can be seen that the coolant flow from the tracer inlet pipe moves in spiral in the descending annular channel. To quantify the angle of rotation of the flow, this surface was unfolded to a plane. The result of this operation is shown in Fig. 6.

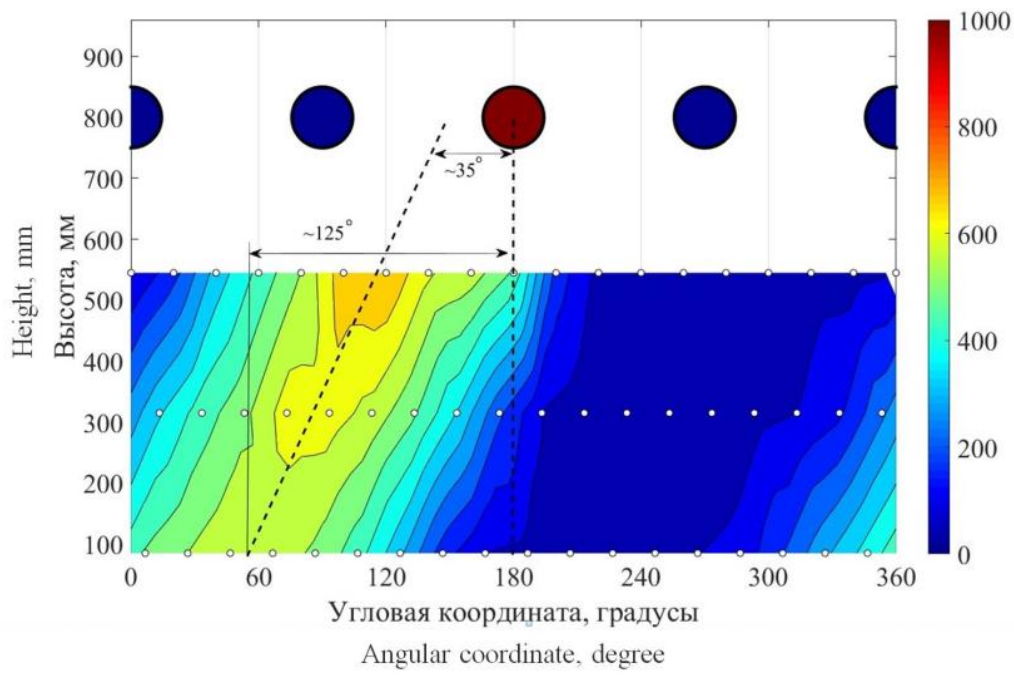

Fig. 6. Visualization of the experimental tracer distribution in the model's annular channel 
The results of visualization allowed us to determine that the flow of the coolant from the circulation loop with the tracer immediately at entrance to the descending annular channel is displaced by an angle of $\sim 30-35$ degrees. This is probably caused by the impact of the flow against the inner wall of the annular chamber. Then the downward movement occurs in a spiral, while the intensity of the twist remains constant throughout the descent annular channel.

Before entering the lower pressure chamber, the maximum concentration of the tracer shifted by an angle of 125-130 degrees from the axis of the inlet pipe. There is no intensive blurring of the tracer spot across the flow in the annular chamber, which indicates a small influence of turbulent diffusion compared to convective transport. There are also no large transverse vortices in this area.

\section{Visualization of the coolant mixing in the lower pres- sure chamber}

Graphical visualization of the flow in the pressure chamber of the reactor model consisted in constructing a cartogram of the tracer concentration distribution at the entrance to the core simulation channels. To do this, layers containing graphical objects describing the model construction were applied sequentially, and were colored. The paint color of the simulator channels was determined depending on the set minimum and maximum values of the tracer concentration in accordance with the standard scale in Matlab colormap ('jet') . The result of this procedure is shown in Fig. 7.

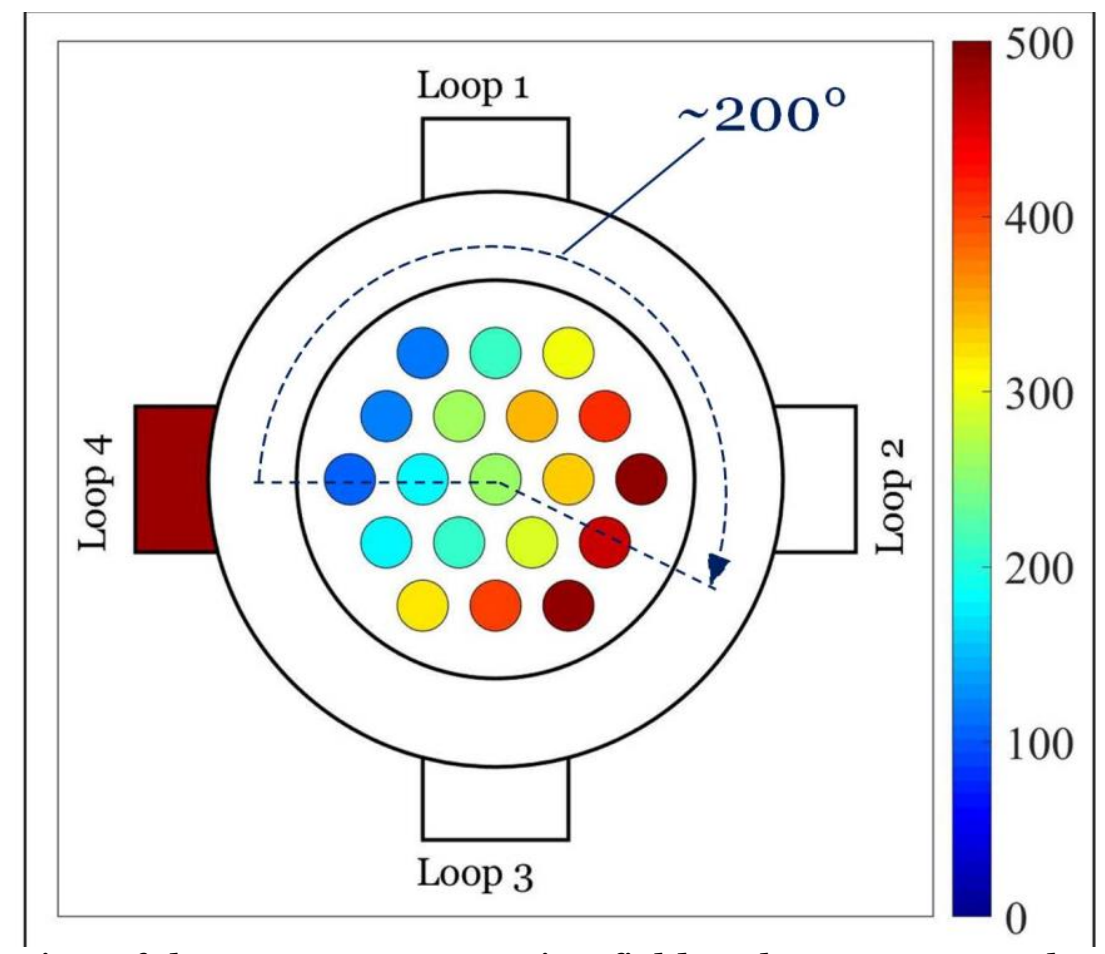

Fig. 7. Visualization of the tracer concentration field at the entrance to the core simulation channels.

The analysis of Fig. 7 allowed us to determine that the maximum value of the tracer volume concentration at the entrance to the core simulation channels is rotated at an angle of 190-200 degrees from the inlet pipe. In comparison with the tracer distribution in the descending annular channel, the flow in the pressure chamber made an additional twist at an angle of 60-70 degrees. At the same time, the maximum value of the tracer concentration remains in the peripheral channels, which indicates a relatively weak mixing in the lower chamber. The rotation of the tracer spot may indicate the presence of a large axial vortex. 


\section{Conclusion}

Using the method of injection of a passive contrast tracer to one of the four coolant circulation loops, the values of the tracer volume concentration were obtained at separate points in the model nuclear reactor pressure vessel.

The tracer concentration fields obtained during visualization and data processing allowed us to analyze the features of movement and mixing of the coolant loop flows. The experimental values of the concentration of the tracer can be used to validate the calculations in the programs of computational fluid dynamics and calibration of their mathematical models.

The developed method of visualization of experimental results obtained at the test facility was implemented in the Matlab software package and compiled into an executable graphical application for Windows [18].

In future, after upgrading the experimental model and including it in the large-scale thermophysical stand "Stand for research of mixing of non-isothermal flows" of the NNSTU, the developed application will be used for visualization and analysis of the temperature field of the coolant. This will significantly reduce the time of processing and analysis of the received information due to its visual presentation in automated mode.

\section{Gratitude}

The research was supported by Russian Science Foundation (project № 18-19-00473).

\section{References}

1. Farkas I., Hutly E., Farkas T., Takaxs A., Guba A., Toth I. Validation of computational fluid dynamics calculation using Rossendorf coolant mixing model flow measurements in primary loop of coolant in a pressurized water reactor model // Nuclear engineering and technology, №48, 2016, P. 941-951. doi: 10.1016/j.net.2016.02.017.

2. Bucalossi, A., Moretti, F., Melideo, D., Del Nevo, A., D’Auria, F., Hohrne, T., Lisenkov, E. and Gallori, D. (2011) Experimental Investigation of In-Vessel Mixing Phenomena in a VVER-100o Scaled Test Facility during Unsteady Asymmetric Transients. Nuclear Engineering and Design, 241, 3068-3075. doi: 10.1016/j.nucengdes.2011.05.005

3. Qingqing Feng, Ulrich Bieder, Thomas Höhne, Analysis of Buoyancy-Driven Flow in the Rocom Test Facility, Energy Procedia, Volume 127, 2017, Pages 44-53, doi: 10.1016/j.egypro.2017.08.062.

4. M. Boumaza, F. Moretti, R. Dizene, Numerical simulation of flow and mixing in ROCOM facility using uniform and non-uniform inlet flow velocity profiles, Nuclear Engineering and Design, Volume 280, 2014, Pages 362-371, doi: 10.1016/j.nucengdes.2014.10.018.

5. Xing Li, Peiyao Qi, Tingjie Zhao, Shouxu Qiao, Sichao Tan, LIF study of temporal and spatial fluid mixing in an annular downcomer, Annals of Nuclear Energy, Volume 126, 2019, Pages 220-232, doi: 10.1016/j.anucene.2018.11.006.

6. Rohde U., Kliem S., Hohne T., Karlsson R., Hemstrom B., Lillington J., Topipila T., Elter J., Bezrukov Y. Fluid mixing and flow distribution in the reactor circuit, measurement data base // Nuclear Engineering and Design, №235, 2005, P.421-443. doi: 10.1016/j.nucengdes.2004.08.045.

7. S. Kliem, A. Grahn, Y. Bilodid, T. Höhne, A realistic approach for the assessment of the consequences of heterogeneous boron dilution events in pressurized water reactors, Nuclear Engineering and Design, Volume 349, 2019, Pages 150-161, doi: 10.1016/j.nucengdes.2019.04.038.

8. Yu Weng, Haitao Wang, Benan Cai, Hongfang Gu, Haijun Wang, Flow mixing and heat transfer in nuclear reactor vessel with direct vessel injection, Applied Thermal Engineering, Volume 125, 2017, Pages 617-632, doi: 10.1016/j.applthermaleng.2017.07.040. 
9. Dmitriev S.M. , Dobrov A.A., Doronkov D.V., Pronin A.N., Solntsev D.N., Sorokin V.D., Khrobostov, A.E. The study of hydrodynamic processes of a coolant flow in FAKVADRAT PWR with various mixing spacer grids // Thermophysics and Aeromechanics, Volume 25, Issue 5, 2018, P. 695-703. DOI: 10.1134/So869864318050062.

10. Dmitriev S.M., Varentsov A.V., Dobrov A.A., Doronkov D.V., Pronin A.N., Sorokin V.D., Khrobostov A.E. Computational and Experimental Investigations of the Coolant Flow in the Cassette Fissile Core of a KLT-40S Reactor // Journal of Engineering Physics and Thermophysics Volume 90, Issue 4, 2017, P. 941-950. DOI: 10.1007/s10891017-1641-7.

11. Dmitriev S.M., Dobrov A.A., Pronin A.N., Ryazanov A.V., Solntsev D.N. Calculation and experimental studies of coolant hydrodynamics in the inlet region of fuel assembly // Journal of Physics: Conference Series, Volume 1128, Issue 1, 2018, paper № 012125. DOI: 10.1088/1742-6596/1128/1/012125.

12. Dmitriev S.M., Khrobostov A.E., Legchanov M.A., Dobrov A.A. Experimental studies and numerical simulation of coolant hydrodynamics in the inlet area of nuclear reactor fuel assembly // MATEC Web of Conferences, Volume 245, 2018, paper № 09017. DOI: 10.1051/matecconf/201824509017.

13. Barinov A.A., Dmitriev S.M., Dobrov A.A., Doronkov D.V., Khrobostov A.E., Pronin A.N., Ryazanov A.V., Solntsev D.N., Zorina O.S. Description of the experimental studies of coolant mixing flows in the reactor pressure vessel // Journal of Physics: Conference Series. - 2018. - №1128 012028, doi :10.1088/1742-6596/1128/1/012028.

14. Dmitriev S.M., Varentsov A.V., Dobrov A.A., Doronkov D.V., Legchanov M.A., Khrobostov A.E. Study of coolant mass transfer behind the VBER-300 FA mixing grids in order to substantiate their effectiveness [in Russian]// Transactions of NNSTU n.a. R.E. Alekseev, №5(102), 2013, P.197-205.

15. Dmitriev S.M., Legchanov M.A., Khrobostov A.E., Varentsov A.V., Dobrov A.A. Studies of local hydrodynamics and intercell mass transfer of the coolant flow in the area of guide channels of fuel assemblies of PWR reactors [in Russian] // Promyshlennaya Energetika, №12, 2013, P.45-50.

16. Dmitriev S.M., Barinov A.A., Dobrov A.A., Doronkov D.V., Pronin A.N., Ryazanov A.V., Solntsev D.N., Sorokin V.D. Experimental studies of turbulent mixing processes in the main equipment of the nuclear power plant [in Russian] // Problems of atomic science and technology. Series: Nuclear and Reactor Constants, №3, 2018, P.120-126.

17. Delnov V.N., Levchenko Yu.I., Shepelev S.F. Superposition method for modeling the temperature field in heat exchange devices by the tracer concentration field [in Russian] // Izvestiya vuzov. Yadernaya Energetika, №3, 2009, P. 152-160.

18. Dobrov A.A., Khrobostov A.E., Solntsev D.N., Pronin A.N., Ryazanov A.V., Ershova M.I. IYaEiTF-FT45 // The Certificate on State Registration of the Computer Program, RU2018617341, 22.06.2018. 